\title{
CHARACTERIZATION AND SOLUBILIZATION OF CHITOSAN FROM THE ORIENTAL HORNET (VESPA ORIENTALIS)
}

\author{
By
}

MAGDA H. RADY ${ }^{1}$, EMAN E. ESSA ${ }^{1 *}$, SHIREEN A. M. MA'MOUN ${ }^{1}$, SHIMAA A. A. MO' MEN ${ }^{1}$, MOHAMMAD S. SALAMA', EMAD M. S. BARAKAT', AND WAEL S. I. ABOU-ELMAGD ${ }^{2}$

Department of Entomology ${ }^{1}$ and Department of Chemistry ${ }^{2}$, Faculty of Science, Ain Shams University, Cairo 11566, Egypt

( ${ }^{\star}$ Correspondence: eman_smile2008@yahoo.com)

\begin{abstract}
Chitosan was extracted from the oriental hornet, Vespa orientalis (L.), Vespinae, Order; Hymenoptera, as a new source of insect chitosan, using chemical methods. We assessed the physical properties of the wasp's chitosan using different approaches including: preliminary color-change identification, Fourier Transform Infrared spectroscopy (FTIR), X-ray diffraction and Nuclear Magnetic Resonance spectroscopy $\left({ }^{1} \mathrm{H}-\mathrm{NMR}\right)$. The results showed that it gave a higher purity, solubility and Degree of Deacetylation (DD) compared to crustacean chitosan. Also, it is soluble in a very low concentration of acetic acid from $0.25 \%$ to $0.5 \%$ while that of Crustacea was soluble in more than $1 \%$ acetic acid, so the oriental hornet could be a novel alternative source of higher pure and more soluble chitosan.
\end{abstract}

Keywords: Egypt, Oriental hornet, Chitosan solubility, Deacetylation degree.

\section{Introduction}

Chitosan is one of the most frequently cited polymers in the scientific research dealing with a wide range of biopharmaceutical and biomedical applications together with food science and technology (AbdElhady et al, 2012; Bellich et al, 2016). Chitosan is derived by the deacetylation of chitin (QI $e t$ $a l, 2004)$. Chitin is one of the major components of the cuticle, tracheae, and peritrophic matrix of insects (Nemtsev et al, 2004; ElShehaby et al, 2011).

The majority of studies of chitin and chitosan refer to the isolation and properties of these substances from the shells of commercially harvested crustaceans, because this is the most readily available material for largescale manufacturing. However, recent works describe the obtaining of chitin and chitosan from the cuticle of insects. At first glance, these sources are not appropriate for industrial manufacturing; however, certain species of insects can be used for accumulation of a large amount of chitin-containing material that is suitable for industrial processing. These are insects that can be reared or obtained through field collection in accumulation as wasps, honeybees, silkworms, and synanthropic flies (Nemtsev et al, 2004). This new source provide no seasonal limitation accessibility to raw materials, low inorganic salt contentand no regional limit to industrial production. Due to the availability of the corpses of wasps in the Apiculture fields in a huge amount manufacturing can be done on a large scale (Ibitoye et al, 2018).

In previous research on chitosan, the most common solvents for chitosan dissolution have been acetic acid solution (Chen et al, 2007). The difficulties in solubilizing chitosan is the main problem facing many researchers even in acetic acid solution, this problem hinder many applications including preparation and synthesis of chitosan nanoparticle compounds so a new method will be discussed in the current work to improve chitosan solubility.

In the present study, Chitosan was extracted from the oriental hornet (Vespa oriental$i$, a social insect of the family Vespidae), which is a primary pest to honey bees, attacking bee colonies to obtain honey and animal proteins (Glaiim, 2009). The oriental hornet physical properties were characterized by using a variety of approaches includ- 
ing: preliminary color-change identification, FTIR, X-ray diffraction and ${ }^{1} \mathrm{H}-\mathrm{NMR}$. The improving its solubility was studied (Castro et al, 2012; Murugan et al, 2015; 2017).

\section{Materials and Methods}

The local resource used to obtain chitin was Vespa orientalis collected from the Apiculture Research Department, Plant Protection Research Institute, Agricultural Research Center, Dokki, Egypt. Wasps were collected after sting removal. Chitosan $85 \%$ degree of deacetylation and 100 cps viscosity was purchased from Shanghai Bioscience \& Technology Co. Ltd., China. All the chemicals used (for example: iodine, potassium iodide, sulfuric acid, ethanol, hydrochloric acid, sodium hydroxide etc.) were purchased from Sigma-Aldrish.

. The chitin was extracted from Vespa orientalis following the standard procedure mentioned in (Majtán et al, 2007) with little modifications. Wasps corpses were washed several times with water and dried at $50{ }^{\circ} \mathrm{C}$ overnight in a dry heat incubator, specimens were mechanically grinded in a mixer. Demineralization step was carried out by treatment with $1.0 \mathrm{M} \mathrm{HCl}$ solution to solid ratio $15 \mathrm{~mL} / \mathrm{g}$. at $100^{\circ} \mathrm{C}$ for $20 \mathrm{~min}$. The resulted solid fraction was washed with distilled water till neutral $\mathrm{pH}$ value was recorded. De-proteinization was performed using alkaline treatment with $1.0 \mathrm{M}$ sodium hydroxide at $85^{\circ} \mathrm{C}$. Treatment was repeated several times during $24 \mathrm{~h}$ and washed with distilled water until $\mathrm{pH}$ value became neutral. Pigment traces responsible for the brown color of this product were removed using a mild oxidizing treatment $\left(\mathrm{H}_{2} \mathrm{O}_{2} / 33 \%\right.$ HCl 9:1, v:v.) (Arbia et al, 2013). Finally, lightly brown chitin was washed with distilled water and dried at $50^{\circ} \mathrm{C}$ in a dry heat oven. The resulted chitin was then washed with distilled water until neutralization.

The extracted chitin from Vespa orientalis was treated with $50 \% \mathrm{NaOH}$ at $100{ }^{\circ} \mathrm{C}$ for 2 $\mathrm{h}$ on a hot plate. The mixture was stirred after some times for homogenous reaction. Samples were then cooled for $30 \mathrm{~min}$ at room temperature, after cooling samples were washed continuously with $50 \%$ of $\mathrm{NaOH}$ and filtered in order to retain the solid matter. This solid matter was further washed with deionized water and dried in oven at $120{ }^{\circ} \mathrm{C}$ for $24 \mathrm{hrs}$ (Prakasam and Azariah, 1975). The modification in this step (deacetylation) was achieved by the repetition of deacetylation process for additional time only for the obtained poorly soluble chitosan in $1 \%$ acetic acid, this time differ according to solubility degree of the produced chitosan (Majtán et al, 2007).

Process of deacetylation of chitin to chitosan was ensured using confirmatory test (Kumar and Verma, 2012), $5 \mathrm{ml}$ of Iodine solution $\left(\mathrm{I}_{2}\right)$ /potassium iodide $(\mathrm{KI})$ solution was added to a test tube with traces of chitosan and another one without chitosan, considered as control, the solution takes the yellow color of iodine. Concentrated sulphuric acid $\left(\mathrm{H}_{2} \mathrm{SO}_{4}\right)$ was added to each tube; the change of color from yellow/brown to dark purple confirms the presence of chitosan.

The wasp chitosan powder $(0.1 \mathrm{~g}$ in triplicate) were placed into a centrifuge tube (known weight) then dissolved with $10 \mathrm{ml}$ of $2,1,0.5,0.25 \%$ acetic acid by hand shaking for $5 \mathrm{~min}$. The solution was then immersed in a boiling water bath for 10 minutes, cooled to room temperature $\left(25^{\circ} \mathrm{C}\right)$ and centrifuged at $10,000 \mathrm{rpm}$ for $10 \mathrm{~min}$. The supernatant was decanted. The undissolved particles were washed in distilled water ( $25 \mathrm{ml})$ then centrifuged a $10,000 \mathrm{rpm}$. The supernatant was removed and undissolved pellets dried at $60^{\circ} \mathrm{C}$ for $24 \mathrm{hr}$, and then weighed the particles and determined the solubility\% (Sun et al, 2016).

The degree of deacetylation (DD) of chitosan was measured by titration method (Abdou et al, 2008). Chitosan (0.5 g) was weighed and dissolved individually in 20 $\mathrm{mL} 0.3 \mathrm{~N}$ HCL at room temperature. Distilled water $(400 \mathrm{~mL})$ was added, and then the wasp chitosan solution was titrated with $1 \mathrm{~N} \mathrm{NaOH}$ solution. A titration curve of $\mathrm{pH}$ assending values vs. $\mathrm{NaOH}$ titration volume 
was produced. The curve's inflection points were found for each indicated transition, then, $\mathrm{NaOH}$ volume at each inflection point was applied to the equation (Eq. 1): $\mathrm{DD} \%=$ 16.1(y-x)/WEq. Where $\mathrm{W}=$ chitosan weight used $(0.5 \mathrm{~g}), \mathrm{X}=$ the first inflection point on the graph of measured $\mathrm{pH}$ vs. titration volume, and $\mathrm{y}=$ the second inflection point.

FTIR spectra of chitosan from wasp were recorded with FTIR (4100Jasco-Japan) spectrophotometer. The spectral region between 4000 and $400 \mathrm{~cm}^{-1}$ was scanned. Specimens were prepared as $\mathrm{KBr}$ pellets. Dried wasp's chitosan powder was mixed thoroughly with $\mathrm{KBr}$ and then pressed to form an ultimate thin homogenous disc with a thickness of $0.5 \mathrm{~mm}$. The wasp's chitosan concentration in the samples was $2 \%$ calculated with respect to $\mathrm{KBr}$.

XRD analysis estimated the crystallinity of the prepared chitosan. The XRD measure ments on powder samples were done using a PANalyticalX'Pert PRO X-ray machine in Faculty of Science Ain-Shams University. $\mathrm{X}$-ray source was $\mathrm{Cu} \mathrm{Ka}$ radiation $(45 \mathrm{kV}$, 30mA). Wasps's chitosan samples were scanned from $26=5-40^{\circ}$ at a scanning rate of $4 \mathrm{~min}^{-1}$ and temperature $25^{\circ} \mathrm{C}$ (Islam et al, 2011). Intensities of the peaks at 110 lattices $\left(\mathrm{I}_{110}\right.$, at $26=20^{\circ}$ equivalent to maximum.

${ }^{1} \mathrm{H}-\mathrm{NMR}$ spectra were measured on Varian Gemini $300 \mathrm{MHz}$ spectrometer, with chemical shift $(\delta)$ expressed in ppm downfield with tetramethylsilane (TMS) as internal standard, in DMSO-d6 and coupling constants $\mathrm{J}$ in $\mathrm{Hz}$ were measured at Microanalytical center, Cairo University.

\section{Results}

The results are shown in table (1) and figures $(1,2,3,4 \& 5)$.

Table 1: Solubility of wasp chitosan before and after re-deacetylation.

\begin{tabular}{|l|c|c|c|c|c|c|c|}
\hline Items & \multicolumn{3}{|c|}{ Before Re-deacetylation } & \multicolumn{4}{|c|}{ After Re-deacetylation } \\
\hline Acetic acid conc. & $0.5 \%$ & $1 \%$ & $2 \%$ & $0.25 \%$ & $0.5 \%$ & $1 \%$ & $2 \%$ \\
\hline Wasp chitosan solubility & $20 \%$ & $43.1 \%$ & $69.9 \%$ & $100 \%$ & $100 \%$ & $100 \%$ & $100 \%$ \\
\hline Commercial chitosan solubility & $22 \%$ & $75.7 \%$ & $98 \%$ & - & - & - & - \\
\hline
\end{tabular}

Solubility degree of wasp chitosan was measured using different concentrations of acetic acid in atrial to increase chitosan solubility wasp chitosan after extraction process demonstrated weak solubility at concentrations $(0.5,1,2 \%)$ of acetic acid while after an additional step of deacetylation, the solubility increased to $100 \%$ at $(0.25-2 \%)$ acetic acid. This excellent solubility was done after repeating the deacetylation step, the co-mmercial chitosan (without any treatment), showed slightly moderate solubility $75.7 \%$ at $1 \%$ acetic acid and $98 \%$ at $2 \%$ acetic acid.

\section{Discussion}

The recovery rate of chitosan extracted from the oriental hornet was $12.2 \%$; whereas that from the black tiger shrimp head was $14.6 \%$ (Tsai et al, 2011), however yield was moderately low as compared to crabs and other crustaceans, This may be due to less amount of chitin in exoskeleton of the oriental hornet. By comparing the reported insect species the oriental hornet gave much higher yield comparing to Periplaneta americana which gave $2.0 \%$ and $26.2 \%$ for the blowfly, Chrysomuia albiceps (Song et al, 2013). The change of the pale yellow color of the extracted chitosan (Fig. 1a) and the whole solution was changed to the deep purple color by adding the concentrated sulphuric acid that proved the success of chitosan extraction (Fig.1b).

One step of deacetylation was sufficient to convert chitin into chitosan in all tested samples but the rate of solubility was less than that of crustaceans but after increasing time of deacetylation as an additional step of deacetylation the solubility was enhanced. The difficulties in solubilizing chitosan is the main problem facing many researchers as it hinder many applications including preparation and synthesis of chitosan nanoparticle compounds.

The solubility of chitosan in acetic acid is a mark of its purity. The lower acid concen- 
tration used, the higher the purity of chitosan (Mohammed et al, 2013). The purity level of chitosan was a factor which affects not only the biological properties like immunogenicity or biodegradability, but also has a profound effect on its solubility and stability (Szymańska and Winnicka, 2015). Most crustacean chitosan and that isolated from different sources dissolved in 1-3\% acetic acid (Ghaly et al, 2018). While the isolated wasp chitosan completely dissolved in 0.25 $0.5 \%$ acetic acid and this is a mark that our isolated wasp chitosan has a higher purity than the commercial one, this excellent solubility which wasn't obtained from any other chitosan due to the entered modification in the isolation procedure (repeating deacetylation step for another period after complete isolation).

The degree of deacetylation (DD) of chitosan is the most important parameter that influences their various properties including biological, physicochemical and mechanical properties and it depends on the method of isolation and the reaction conditions should be taken into consideration prior to the use of chitosan as drug delivery system (Khan et $a l$, 2002). No doubt, the DD of wasp chitosan exhibited the highest (92-93\%), while commercial chitosan had lower DD (83.8$85.8 \%)$.

In the present study, FTIR spectra of chitosan obtained from wasp and crustacean chitosan were recorded with a Nicolet FT-IR (4100Jasco-Japan).The chemical structure of the chitosan derived from Vespa orientalis was confirmed by FTIR analysis. FTIR Spectrum of chitosan showed characteristic peaks at 3500, 3300 and (br) $3448 \mathrm{Cm}^{-}$ ${ }^{1}$ which indicated symmetric stretching vibration of $\mathrm{OH}$ and amine groups. Absorption peaks at 2918 and $2884 \mathrm{Cm}^{-1}$ indicated the presence of $\mathrm{CH}$ stretch, Absorption band at 1654 was due to $\mathrm{C}=\mathrm{O}$ stretching (amide $\mathrm{I}$ ) and peaks at 1081, 1033 corresponding to C$\mathrm{O}$ stretching. Peak at 894.91 was a ring stretching characteristic for $\beta-1-4$ glycosidic linkage. FTIR spectra of wasp chitosan was to a large extent similar to the FTIR Spectra analysis of chitosan carried out by many authors (Brugnerotto et al, 2010; Anicuta et al, 2010; Ramya et al, 2012; Marei et al, 2016).

In the present study, XRD patterns of the chitosan from shrimp exhibited two sharp $\left(9.4 \& 20.2^{\circ}\right)$ and two faint $\left(22.0 \& 26.8^{\circ}\right)$ diffraction peaks. While that from wasp showed two sharp peaks at $10.4,20^{\circ}$ and one faint $22.1^{\circ}$. Similar peaks were reported in a chitin and chitosan structures obtained from different organisms such as insects, crustaceans, entozoa and fungi (Ifuku et al, 2011; Wang et al, 2013; Kaya et al, 2014). The two sharp peaks appeared at around 10 and $20^{\circ}$ that corresponding to the $\left(\begin{array}{lll}0 & 2 & 0\end{array}\right)$ and (1 $10)$ planes of the crystalline lattice are classically characterized chitosan (Lai et al, 2010; AbdElhady, 2012; Marei et al, 2016).

In the present study, ${ }^{1} \mathrm{H}-\mathrm{NMR}$ spectrum showed singlet peaks at 1.8 and at $4.6 \mathrm{ppm}$ corresponding to $\mathrm{CH}_{3}$ of acetyl group and $\mathrm{H}-1$ (Ac) of acetylated chitosan respectively, beside the characteristic peaks of deacetylated chitosan at 2.9, 3.4-3.9 and 4.7 ppm.

Undoubtedly, more support for the structure and the ratio of acetylated and deacetylated chitosan were gained from ${ }^{1} \mathrm{H}-\mathrm{NMR}$ revealed that the percentage of methyl group of the acetamido group of acetylated chitosan at $\delta=1.8 \mathrm{ppm}$ decreased and degree of deacetylation increased with increasing time of deacetylation (Vongchan et al, 2002).

\section{Conclusion}

The characteristics of produced wasp chitosan were in accordance with the commercial standard. The investigation revealed that the wasp has lower yield of chitin of $12.2 \%$ but of higher purity compared to that of the shrimp. The degree of deacetylation (DDA) was determined. It was found that the DD of chitosans derived from wasp cuticles are found to be comparable (92-93\%) and higher than that of chitosan from shrimps $(75 \%)$. X-ray powder diffraction (XRD) showed that the wasp's chitosan had higher crystallinity than that of the shrimp. 
Chitosan with such properties has several commercial applications and greater scope of industrial applications and these results encourage us to continue the study of this kind of chitosan. Further studies in this area are ongoing progress and will be published in due time elsewhere.

Author Contribution: Magda Rady, Wael Abou-Elmagd and Eman Essa conceived the idea and designed the plain. Eman Essa, Shreen Ma'moun and Shimaa Mo'men conducted the practical work. Mohamed Salama, Emad Barakat and Shreen Ma'moun contributed material. Eman Essa, Magda Rady and Wael Abou-Elmagd wrote the manuscript. All authors approved the manuscript.

Conflict of interest: The authors declared that they neither have conflict of interest nor received fund.

ORCID:

Essa, EE， http://orcid.org/0000-0003-12306333

\section{References}

AbdElhady, MM, 2012: Preparation and characterization of chitosan/zinc oxide nanoparticles for imparting antimicrobial and UV protection to cotton fabric. Hindawi 2012, Inter. J. Carbohyd, Chemist. Article ID 840591, 6 pages. http://dx. doi.org/10.1155/2012/840591

Abdou, ES, Nagy, KS, Elsabee, MZ, 2008: Extraction and character rization of chitin and chitosan from local sources. Bioresou. Technol. 99, 5:1359-67.

Arbia, W, Arbia, L, Adour, L, Amrane, A, 2013: Chitin extraction from crustacean shells using biological methods-a review. Food Technol. Biotechnol. 51, 1:12-6.

Anicuta, SG, Dobre, L, Stroescu, M, Jipa, I, 2010: Fourier transforms infrared (FTIR) spectroscopy for characterization of antimicrobial films containing chitosan. University Politehnica of Bucharest, Fac. Appl. Chemist. Material Sci. 1234-40; e-mail: anicuta_s@yahoo.com

Bellich, B, D'Agostino, I, Semeraro, S, Gamini, A, Cesàro, A, 2016: The Good, the Bad and the Ugly of Chitosans. Marine drugs 14, 5:99102.

Brugnerotto, J, Lizardi, J, Goycoolea, FM, Argüelles-Monal, W, Desbrieres, J, Rinaudo, M, 2001: An infrared investigation in relation with chitin and chitosan characterization. Polymer 42, 8:3569-80.

Castro, SPM, Paulín, EGL, 2012: Is Chitosan a New Panacea? Areas of Application. In: Karunaratne, DN, Ed., The Complex World of Polysaccharides, ISBN: 978-953-51-0819-1, InTech. http://www.intechopen.com/bo

Chen, PH, Hwang, YH, Kuo, TY, Liu, FH, Lai, JY, et al, 2007: Improvement in properties of chitosan membranes using natural organic acid solutions as solvents for chitosan dissolution. J. Med. Biol. Engineer. 27:23-8.

El-Shehaby, M, Salama, MS, Brunner, E, Heinze $\mathbf{J}, 2011$ : Cuticular hydrocarbons in two parapatric species of ants and their hybrid. Integr. Zool. 6, 3:259-65.

Glaiim, MK, 2009: Hunting behavior of the oriental hornet, Vespa orientalis L., and defense behavior of the honey bee, Apis mellifera L., in Iraq. Bull. Iraq Nat. Hist. Mus. 10, 4:17-30. Ghaly, CAF, Bakaar, A, Mohamed, AF, 2018: In vitro assessment of anticancer activity of shrimp derived chitosan and related apoptotic profile alteration. J. Egypt. Soc. Parasitol. 48, 2: 379-88

Gorovoj, L, Burdukova, L, 1996: Chitin produced from fungi: Medicine application perspective. Adv. Chitin Sci. 1:430-9.

Ibitoye, EB, Lokman, IH, Hezmee, MNM, Goh, YM, Zuki, ABZ, Jimoh, AA, 2018: Extraction and physicochemical characterization of chitin and chitosan isolated from house cricket. Biomed. Materi. 13, 2:025009-13.

Ifuku, S, Nomura, R, Morimoto, M, Saimoto, H, 2011: Preparation of chitin nanofibers from mushrooms. Materials 4, 8:1417-25.

Islam, MM, Masum, SM, Rahman, MM, Molla, MAI, Shaikh, AA, Roy, SK, 2011: Preparation of chitosan from shrimp shell and investigation of its properties. Inter. J. Basic Appl. Sci. 11, 1:116-30.

Kaya, M. Cakmak, YS, Baran, T, Asan-Ozusaglam, M, Mentes, A, Tozak, KO, 2014: New chitin, chitosan, and O-carboxymethyl chitosan sources from resting eggs of Daphnia longispina (Crustacea); with physicochemical characterization, and antimicrobial and antioxidant activities. Biotechnol. Bioproce. Engineer.19, 1:58-69.

Khan, TA, Peh, KK, Ch'ng, HS, 2002: Reporting degree of deacetylation values of chitosan: the influence of analytical methods. J. Pharmaceut. Sci. 5, 3:205-12. 
Kumar, D, Verma, AP, 2012: Isolation and degree of deacetylation of chitin from cultured biomass of diatoms. Bionotes 14, 4:116-7.

Lamarque, G, Viton, C, Domard, A, 2004: Comparative study of the second and third heterogeneous deacetylations of $\alpha$-and $\beta$-chitins in a multistep process. Biomacromolecules 5, 5: 1899-907.

Lai, LH, Deng, JC, Deng, HR, Liu, ZL, Xin, L, 2010: Synthesis and characterization of chitosan/ZnO nanoparticle composite membranes. Carbohyd. Res. 345, 8:994-8.

Majtán, J, Bíliková, K, Markovič, O, Gróf, J, Kogan, G, Šimúth, J, 2007: Isolation and characterization of chitin from bumblebee (Bombus terrestris). Inter. J. Biol. Macromolecul. 40, 3: 237-41.

Marei, NH, El-Samie, EA, Salah, T, Saad, G R, Elwahy, AH, 2016: Isolation and characterization of chitosan from different local insects in Egypt. Inter. J. Biol. Macromolecul 82:871-7.

Mohammed, MH, Williams, PA, Tverezovskaya, O, 2013: Extraction of chitin from prawn shells and conversion to low molecular mass chitosan. Food Hydrocolloids 31, 2:166-71.

Murugan, K, Benelli, G, Ayyappan, S, Dinesh, D, Panneerselvam, C, Nicoletti, M, et al, 2015: Toxicity of seaweed-synthesized silver nanoparticles against the filariasis vector Culex quinquefasciatus and its impact on predation efficiency of the cyclopoid crustacean Mesocyclops longisetus. Parasitol. Res. 114, 6: 2243-53. Murugan, K, Anitha, J, Suresh, U, Rajaganesh, R, Panneerselvam, C, et al, 2017: Chitosan-fabricated Ag nanoparticles and larvivorous fishes: A novel route to control the coastal malaria vector Anopheles sundaicus? Hydrobiologia. DOI 10.1007/s10750-017-3196-1

Nemtsev, SV, Zueva, OU, Khismatoullin, RG, Khismatoullin, MR, Varlamov, VP, 2001: Bees as Potential Source of Chitosan. $37^{\text {th }}$ Inter. Apic. Congr. 28 October to 1 November, Durban, South Africa
Nemtsev, SV, Zueva, OY, Khismatullin, MR, Albulov, AI, Varlamov, VP, 2004: Isolation of chitin and chitosan from honeybees. Appl. Biochemis. Microbiol., 40, 1:39-43.

Prakasam, VR, Azariah, J, 1975: An optimum $\mathrm{pH}$ for the demonstration of chitin in Periplanata americana using Lugol's iodine. Acta Histochem. 53, 2:238-40.

Qi, L, Xu, Z, Jiang, X, Hu, C, Zou, X, 2004: Preparation and antibacterial activity of chitosan nanoparticles. Carbohyd. Res. 339, 16:2693-700. Ramya, R, Sudha, PN, Mahalakshmi, J, 2012: Preparation and characterization of chitosan binary blend. Inter. J. Sci. Res. Publ. 2, 10:1-9.

Song, C, Yu, H, Zhang, M, Yang, Y, Zhang, G, 2013: Physicochemical properties and antioxidant activity of chitosan from the blowfly Chrysomya megacephala larvae. Inter. J. Biol. Macromolecul. 60, 347-54.

Sun, B, Quan, H, Zhu, F, 2016: Dietary chitosan nanoparticles protect crayfish Procambarus clarkii against white spot syndrome virus (WSSV) infection. Fish Shellfish Immunol. 54: 241-6.

Szymańska, E, Winnicka, K, 2015: Stability of chitosan: A challenge for pharmaceutical and biomedical applications. Marine Drugs 13, 4: 1819-46.

Tsai, T, Chien, HF, Wang, TH, Huang, CT, Ker, YB, et al, 2011: Chitosan augments photodynamic inactivation of gram-positive and gramnegative bacteria. Antimicrob. Agents Chemother. 55, 5:1883-90.

Vongchan, P, Sajomsang, W, Subyen, D, Kongtawelert, P, 2002: Anticoagulant activity of a sulfated chitosan. Carbohyd. Res. 337, 13:123942.

Wang, Y, Chang, Y, Yu, L, Zhang, C., Xu, X., Xue, Y, Xue, C, 2013: Crystalline structure and thermal property characterization of chitin from Antarctic krill (Euphausiasuperba). Carbohyd/ Polymers 92, 1:90-7.

\section{Explanation of figures}

Fig. 1: a- Pale yellow powder of experimentally obtained chitosan. b- Bright and deep purple color appeared on addition of iodide/potassium iodide aqueous solution $(0.03 \% \mathrm{w} / \mathrm{w})$ and concentrated sulfuric acid aqueous solution $(1 \%, \mathrm{w} / \mathrm{w})$ to chitosan sample.

Fig. 2: a- FTIR spectra of chitosan from oriental hornet. b- Crustacean chitosan from traditional sources. c- Overlay between two spectra.

Fig. 3: XRD patterns of chitosan from a- shrimp (Ramya\&Mahalakshmi 2012) and b- Oriental wasp.

Fig. 4: ${ }^{1} \mathrm{H}-\mathrm{NMR}$ spectra of the chitosan prepared from the oriental hornet, (A)after $2 \mathrm{hr}$ deacetylation (B) after re-deacetylation (4 hr).

Fig. 5: Deacetylated and acetylated monomers of chitosan. 


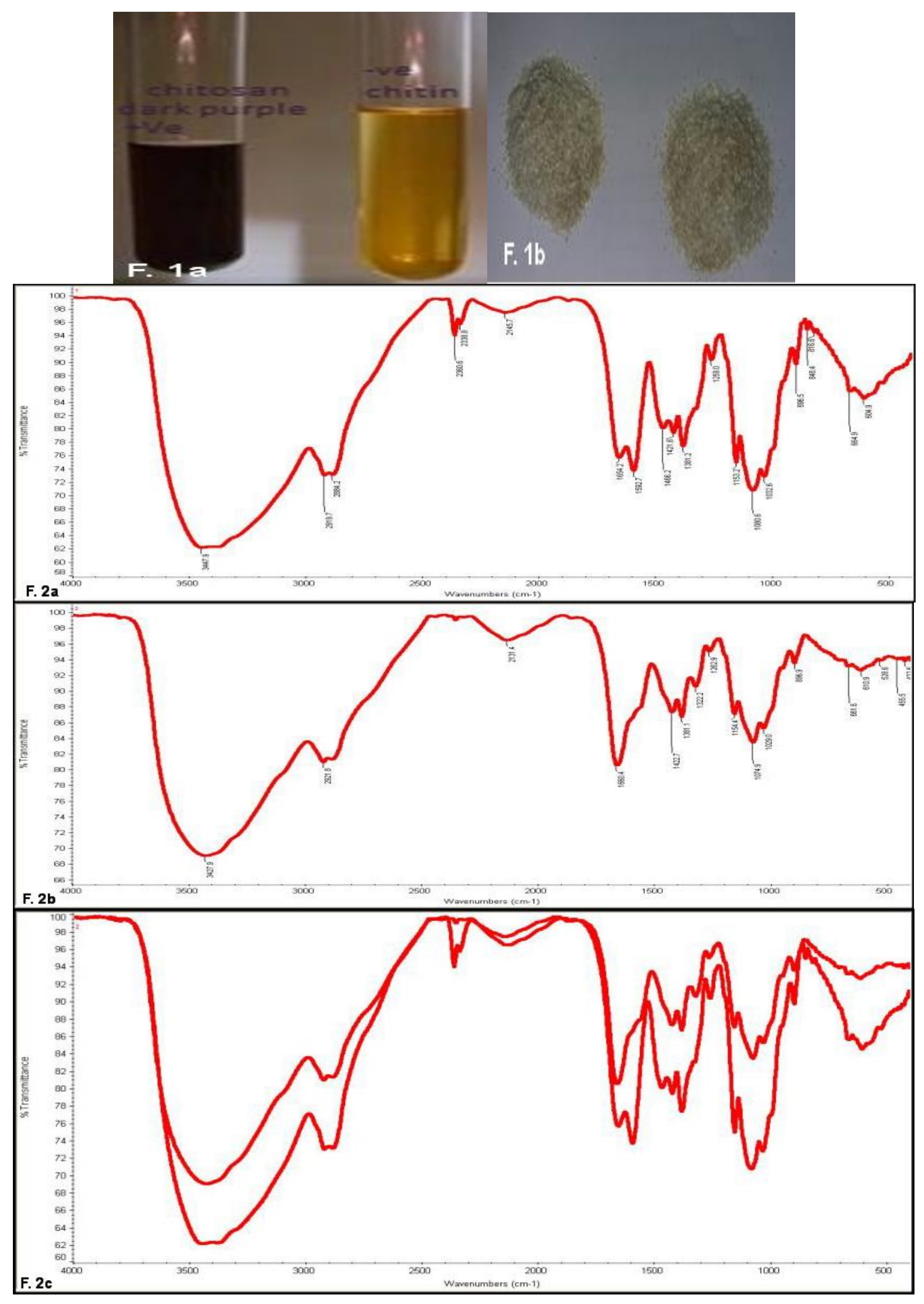




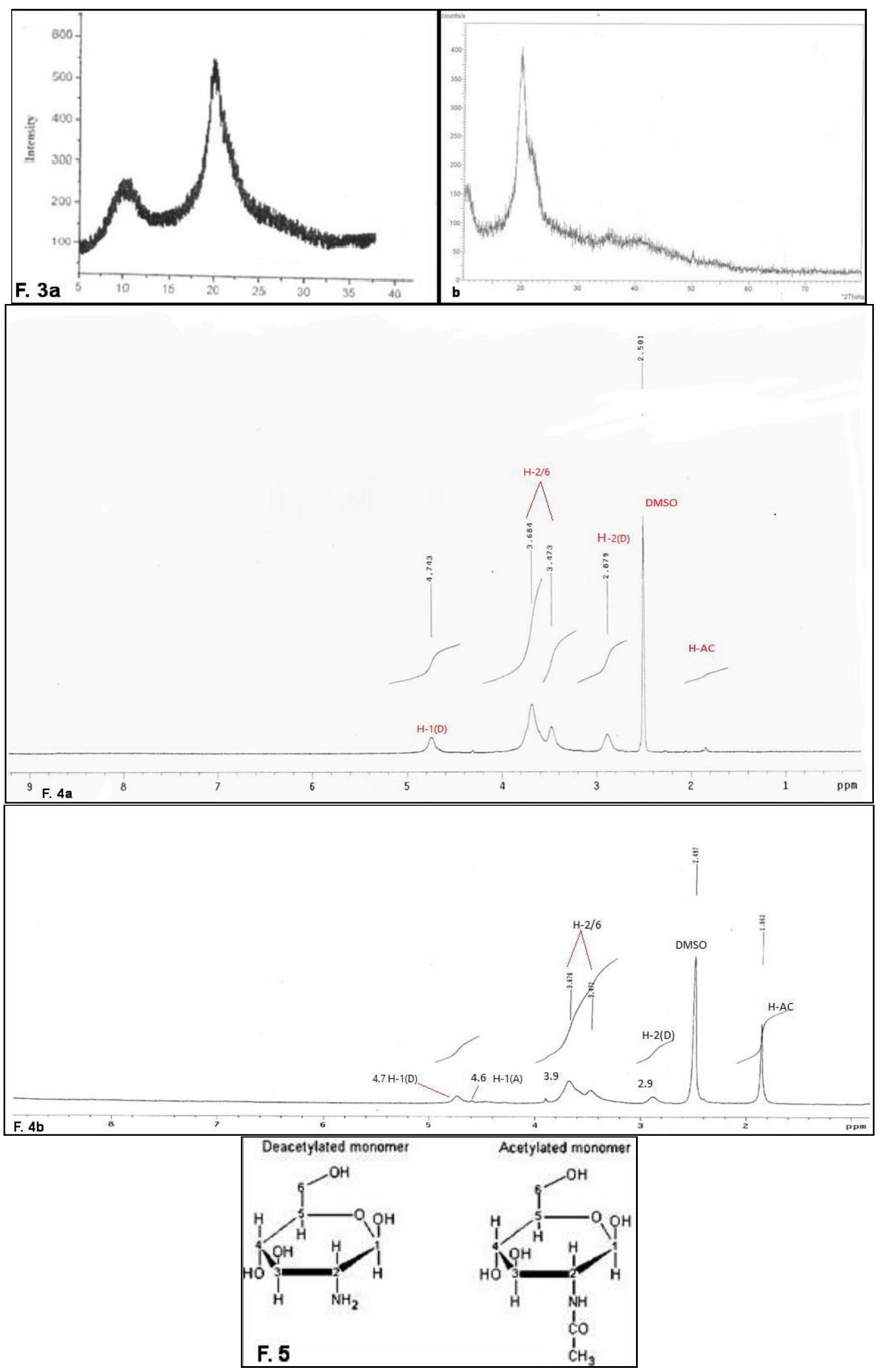

